$\xi=-1$

\title{
Water leakage detection monitoring and controlling system using IOT
}

\author{
P.Swetha Reddy ${ }^{1}$, K.V.Chanakya ${ }^{2}$, B.Eswari ${ }^{3}$, Ch.Bhupati ${ }^{4}$ \\ ${ }^{1,2,3}$ U.G Students, Dept. of E.C.S.E Koneru Lakshmaiah Educational Foundation, Vaddeswaram, Guntur, Andhra Pradesh, India-522502 \\ Associate Professor, Dept. of E.C.S.E Koneru Lakashmaiah Educational Foundation, Vaddeswaram, \\ Guntur, Andhra Pradesh, India-522502 \\ *Email: swe3021@gmail.com
}

\begin{abstract}
The Water is the most valuable because it is a basic need of all humans, in these days water supply department are facing problem because of less amount of water due to less rainfall, lowering of ground water in spite of all these problems water leakage from pipelines while supplying and also no monitoring of water distribution and controlling. With increment in population, neighborhoods have expanded as a result of this reason water has turned into a major issue which influences in distribution, conservation, consumption and also the quality so, to overcome all these problems and create system economical there's want of correct observance and dominant system. In this paper, we are proposing a system which can detect the leakages, monitoring and controlling if water supply in pipelines. Sensors places in the tank which continuously informs the water level of water in the tank. The motor functioning will be automatically turn on and when tank is about to fill up it will cut off.
\end{abstract}

Keywords: Arduino Uno, Flow Sensor, ESP8266, LCD, GSM.

\section{Introduction}

In India more than $30 \%$ of people live in urban areas that are expected to double in population by 2050 . With a increasing economy and dynamical lifestyles the pressure on water resources used for supply purpose is increasing. Most cities in India are with lack of water, with no city having $24 / 7$ water supply. Water is very important for human and animal life for maintain ecological balance and for economic and development activities of all kinds Water is a fundamental need of every people everyone must save the water for the future. Water management in the cities has become a big issue due to lack of rainfall, increase in population many people are facing water problem because they don't have enough amount of water for daily needs. Management of water resource in India is importance to sustain one billion plus population. Because of improper monitoring water cannot be supplied properly, in cities some areas can get proper supply of water and the others areas may have irregular supply there is a need of continuous observing and controlling, of water supply booking and appropriate circulation. Different issues are extreme utilization, flood of tanks and spillage in pipes, interruption in the water supply in the city. For the leakage of the water pipelines there are many other process and also we have some the protocols for water leakage detection and some other for monitoring and controlling. In this paper we discuss about water leakage detection, monitoring and controlling using advanced techniques.

In some papers we have Smart Water Leakage Detection and Monitoring Device By BhekiSithole, SuvendiRimer, Khmaies, C.Mikeka, J.Pinifolo; In this paper they have explained about water leakage detection and monitoring. This paper is exhibiting a variable minimal effort device which is equipped for deciding conceivable spillages in the client's property and announcing current household water consumption levels in real time. Flow meter sensors are used to measure the quantity of water consumed by consumer. In turn, the flow rates of water and amount of water used will be displayed in LCD and the complete information will be send to website. This system has been efficiently and precisely intended to limit commercial losses.

An Enchanced Underground Water Pipeline Water Leakage Monitoring And Detection System Using Wireless Sensor Network ByM.Jayalakshmi, Dr.V.Gomathi: This paper depicts about the plan and execution of a water spillage observing and discovery framework to screen and distinguish spill with the assistance of remote arranged sensors. The goal of this upgraded framework is to identify conceivable underground water spillage for private water pipes that are checked from a PC. In this way, a powerful and dependable wireless sensor organize which forms little Printed Circuit Boards (PCB), information from remote sensors of various sorts (acoustic, weight, temperature, stream rate and so on) are gathered and observed on a Pc to distinguish the correct spillage position. Once a break is identified the water ulitily must make restorative move to limit water misfortunes in the dispersion framework. Along these lines the proposed framework will be utilized to spare water and decreases the supplanting cost.

\section{Proposed System}

Before knowing about the proposed system let us know how water supply is done through pipelines. Water from rivers and lakes reach to the particular area tanks for easy supply to different hous- 
es in an area. The water which are reached to tanks should be supplied to houses equally or else there may be in sufficient of water so for that purpose monitoring of water supply through pipelines should be done and in same way the controlling of water in pipelines should be done due to lack of water. To manage all these problems we need to check the condition of water pipelines before supplying and if any leakage is present in middle of the pipeline that may cause many problems to the people stay in houses. And if any leakage occurs in pipelines it causes wastage of water. The main objective of our project is to design a system which can detect the leakage of pipeline while the supply of water and if any leakage is present in the pipe then automatically the motor will off and the supply stops for that pipe not to have more wastage of water and to manage the flow of water which are supplied so that all can get equal amount of water by using this system.

\section{Related Work}

System consist of Arduino board, LCD, ESP8266, GSM module, flow sensor, power supply each block is explained below. We are working on a prototype model The following block diagram shows the hardware used in the system.

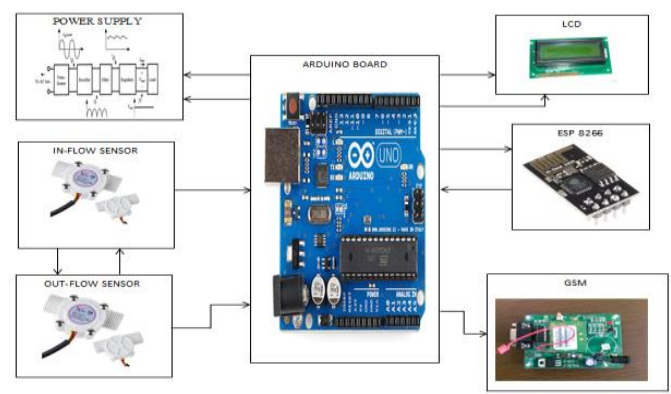

Fig.1 Block diagram of water system

\subsection{Arduino Uno}

Arduino uno could be a microcontroller board in less weight of the ATmega328P. It has fourteen advanced input/output pins (which 6 can be used as Pulse Width Modulation outputs), 6 analog inputs, a $16 \mathrm{MHz}$ quartz crystal, a USB connection, a power jack, and a reset button. Arduino board contains all the supported pins needed for the microcontroller; connect it to a computer with a USB cable or connect to power supply with a AC-to-DC adapter or battery to on the board. In this project we use arduino board for connecting all the required components and power supply is also being done using this board. The inputs and outputs should be connected properly. While connecting the board to remaining devices proper care should be taken.

\subsection{Flow Sensors}

The water flow sensor model used in project is YF-S201, its working range: $1-30 \mathrm{~L} / \mathrm{Min}$ and water pressure: $<=1.75 \mathrm{MpS}$. The arduino flow sensor works on principle of hall effect. Flow sensor is used to determine the mass flow rate of inflow and outflow of water used in the pipelines. In this we use water flow sensor it consists of a plastic valve body, a water rotor and a hall effect sensor. This flow sensor is arranged to both sides of the pipe which can measure the inflow and outflow when water flows through sensor the rotor moves. Speed of water changes with the flow of water. By using this flow sensor can measure the flow rate of water flows in pipelines. Flow sensor is interfaced with arduino board with 3 wires of flow sensor they are $5 \mathrm{~V}$ power supply(Vcc),Ground(Gnd), and signal/pulse line. Connect Vcc and GND of flow sensor to Vcc and Gnd of arduino board, the pulse line of the flow sensor is connected to digital pin 2 of arduino.

\subsection{Liquid Crystal Display (LCD)}

A Liquid Crystal Display (LCD) is a level board show that uses the high balancing properties of fluid crystal. Fluid crystals don't transmit light straightforwardly . In this project LCD display is utilized for the show of inflow and outflow of water through pipelines. If there is any change in the flow of water the leakage will be detected the in the LCD it show that the leakage of water is detected. LCD is interfaced with arduino board by connecting the LCD pins to arduino.

\subsection{ESP8266}

We use ESP8266 Wi-Fi module which is of low cost. It fully consists of TCP/IP stack and microcontroller unit (MCU). It can control any electrical device by using internet from any place in the world. It is easy to use with arduino. For any IoT application this wifi chip can be used for easy connection. ESP8266 module has 3 operational modes they are Access Purpose (AP), Station (STA), Both access purpose and station. Upload ESP8266 code to arduino board from Tools > board > generic ESP8266 module there are three main steps arduino setup, installing ESP8266 platform, controlling input and output.

\subsection{GSM}

Global System for Mobile communication (GSM) is a computerized portable communication framework that is broadly utilized as a part of numerous of world. GSM utilizes a variety of the Time Division Multiple Access (TDMA) and is most generally utilized of three advanced remote communication innovations (TDMA, GSM and CDMA). GSM manages at either the $900 \mathrm{MHz}$ or 1800 $\mathrm{MHz}$ frequency band. In this project GSM is used for getting messages for the registered mobile when leakage is detected. Even the motor is off if the message gets to the mobile by that the repair of the pipe can be done easily.

AT commands are instructions used to control a modem. AT is abbreviation of Attention. In this project we use some of AT commands they are, AT+CMGF is to set in message format for sending to mobile. AT+CMGS is used to send SMS messages for the registered mobile number

\section{Software}

The programming language used in this project is embedded C. It is general purpose programming language we are using for arduino for programming.

The main steps involved in software implementation of arduino are: Verify, Upload, New, Open, Save and Serial.

Additional commands are also found in the software within the menus: File, Edit, Sketch, Tools and Help

\section{Implementation Results}

The connections are made as per the block diagram and made a prototype system. At first the motor will on after power is supplied the water flow through pipelines from inflow of the pipeline and the water go out through the outflow of the pipeline. Then in LCD the inflow and outflow rate of water is displayed there will not be much difference. If any leakage is between the pipeline then the inflow and outflow have more value variation by that we can know that leakage is detected and that will be displayed in LCD. After the leakage is detected then by using GSM can get the message to mobiles and the motor will be accordingly off so that the water does not flow through pipeline.

The display of project board with all the connections made and interface with arduino board is done. 


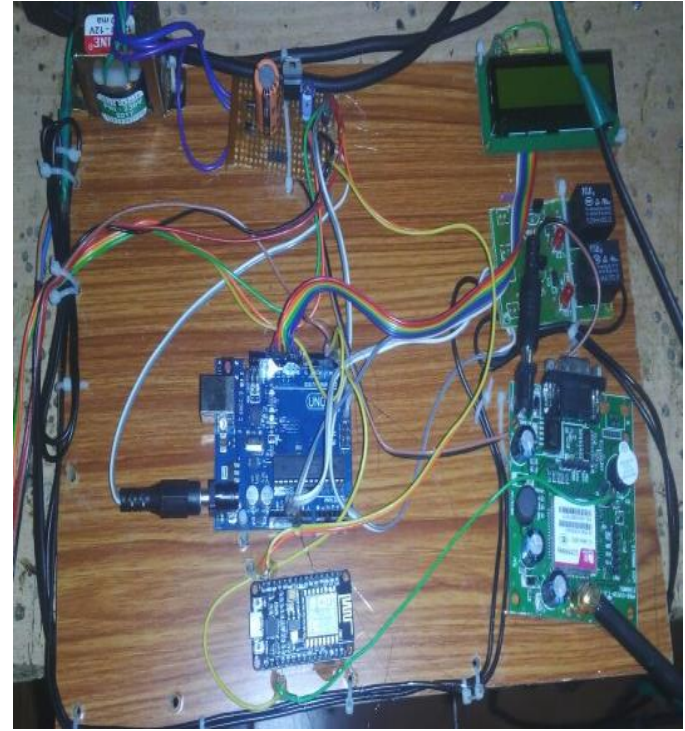

Fig.2 Board with connections

The flow of water in pipeline from inflow to outflow according to the arrangement of the sensor.

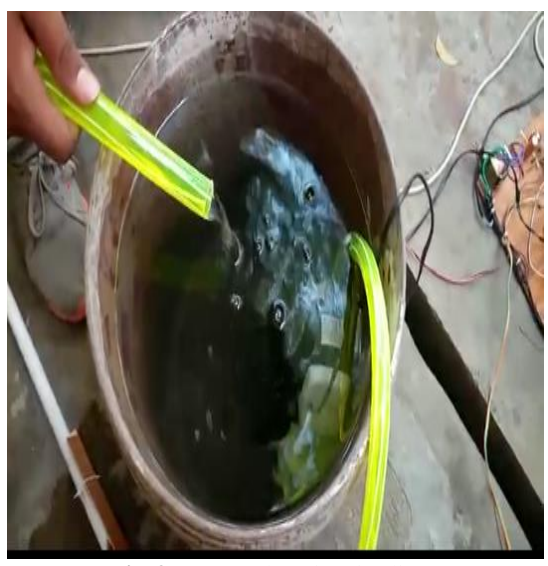

Fig.3 Water Flow in pipelines

The LCD display of inflow and outflow of water with unit L/H. Here we are having a little variation due to having improper arrangement to pipeline.

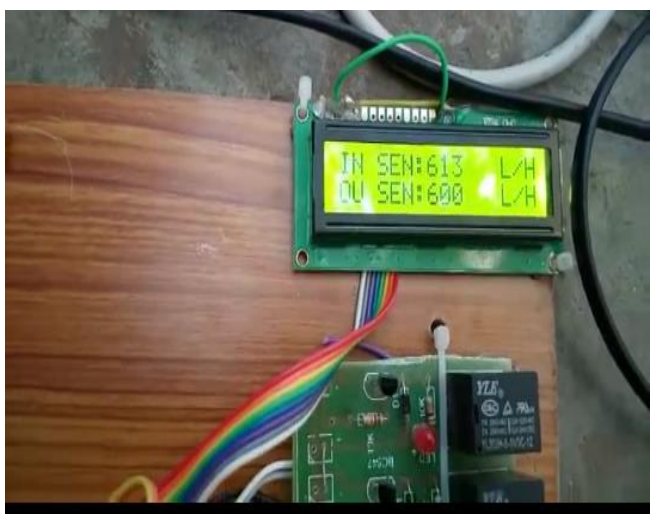

Fig.4 Display of water Inflow and Outflow

To show weather leakage is detected or not in pipeline we have arranged a area for leakage. When leakage is on the water leakage will be detected and motor off so that there will not be any flow of water.

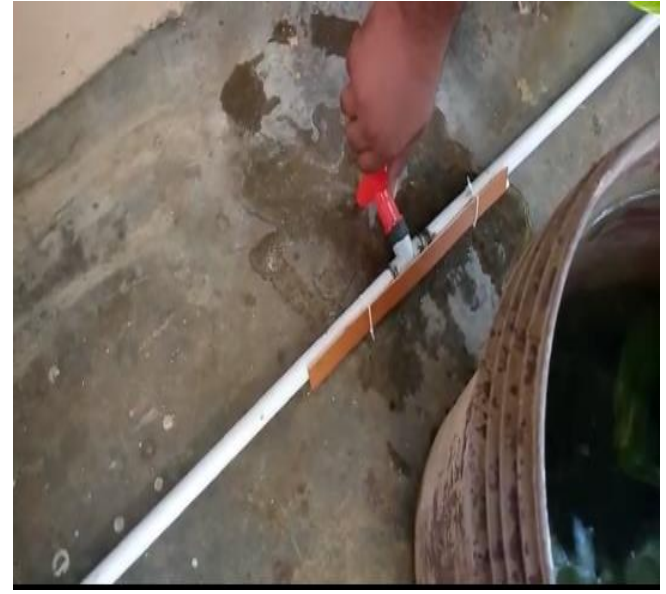

Fig.5 Water leakage area

As the water leakage is done in the LCD it shows that water leakage is detected

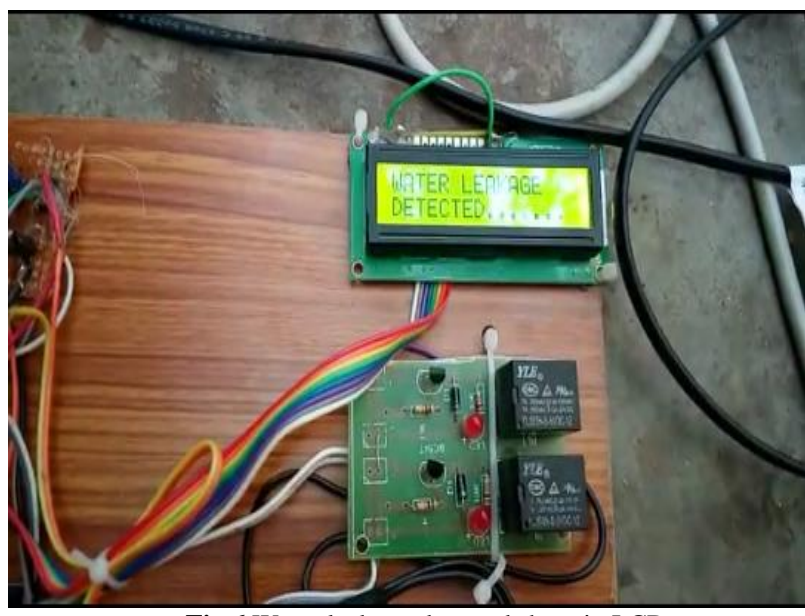

Fig.6 Water leakage detected show in LCD

\section{Conclusion}

Using this system the water leakage can be detected easily and the monitoring of the water also can be done. The monitoring of water can be done by know the flow of through the pipeline during the supply. The water supplied from tank to different houses through pipelines have leakage sometimes due to that leakage there may have lot of water wastage. The controlling of water can be done by automatic off of motor when the leakage is detected in the pipeline so that the flow of water will also be off.

\section{Acknowledgement}

We are thankful to my guide who encouraged us and had faith in us. We would like to express our gratitude towards HOD, professors and entire electronics and computers science engineering department of KLEF college, Guntur for their constant support. Finally I would like to thank all the all authors whose projects

\section{References}

[1] PranithaVijaykumarKulkarni, Mrs. M. S Joshi “An IOT based Water Supply Monitoring and Controlling System with Theft Identification" International Journal of Innovative Research in Science, Engineering and Technology Volume 5, Issue 9, Sep 2016

[2] BhekiSithole,SuvendiRimer,Khmaies,C.Mikela,J.Pinifolo "Smart Water Lekage Detection And Monitoring Device" ISTAfrica 2016, Conference Proceedings Paul Cunningham And 
Miriam Cun imgham(Eds), IIMC(International Information Management Corporation),2016 ISBN:978-1-905824-55-7

[3] Exploring IOT Application Using Raspberry Pi” International Journal of Computer Networks and Application Volume 2,Issue 1,January-February(2015)

[4] M.Jayalakshmi, Dr.V.Gomathi “An Enhanced Underground Water Pipeline Water Leakage Monitoring And Detection System Using Wireless Sensor Network" 2015 International Conference On Soft-Computing And Networks Security (ICSNS), 25-27 Feb. 2015

[5] Riasood, Manjitkaur, HemantLenka "Design and development of Automatic Water Flow Meter" International journal of computer science, engineering and applications vol 3 june 2013

[6] The Internet of Things: A survey

[7] www.arduino.cc

[8] www.developershme.com/sms/atandsintro.asp

[9] ieexplore.ieee.org 